\title{
Exploring the "Green" Transformation Planning of Industrial Parks in the Era of Low Carbon Economy
}

\author{
Caijuan Liang \\ School of Civil Engineering and Architecture, Wuhan University of Technology, Wuhan, China \\ Email: 2075273306@qq.com
}

How to cite this paper: Liang, C.J. (2021) Exploring the "Green" Transformation Planning of Industrial Parks in the Era of Low Carbon Economy. World Journal of Engineering and Technology, 9, 747-754. https://doi.org/10.4236/wjet.2021.94051

Received: August 22, 2021

Accepted: September 11, 2021

Published: September 14, 2021

Copyright $\odot 2021$ by author(s) and Scientific Research Publishing Inc. This work is licensed under the Creative Commons Attribution International License (CC BY 4.0).

http://creativecommons.org/licenses/by/4.0/

\section{(c) (i) Open Access}

\begin{abstract}
The core function of the low carbon economy is to change the economic development trend of the whole society. It is necessary to carry out industrial transformation and upgrading according to the concept of sustainable development and to realize integrated technological innovation and efficient economic development without violating the law of ecological and environmental development. In the era of the low-carbon economy, industrial parks should solidly promote the green transformation planning process. Relying on the basic logical framework of green transformation of industrial parks, it can build a green development quality evaluation system of industrial parks and formulate a green planning mechanism and green economic cycle development model in line with the background of the low-carbon economy.
\end{abstract}

\section{Keywords}

Low-Carbon Economy, Industrial Park, “Green” Transformation Planning

\section{Introduction}

The green development and healthy operation of the industrial economy should be considered in multi-dimensional aspects such as energy efficiency technology, infrastructure sharing, and system green upgrading. The most important symbol of a low carbon economy is the achievement of both economic development goals and ecological environmental protection goals. The intelligent construction and green transformation of industrial parks should be able to do a good job of system upgrading in terms of energy consumption and waste emission. With the leading industry of the industrial park as the key and the production enterprises of the park as the management target, a scientific green transforma- 
tion plan should be designed. The managers need to effectively comprehend the core ideological connotation of a low-carbon economy and take it as the new management concept and the target of green transformation to innovate the management mode of the industrial park and carry out the green transformation of the basic hardware equipment and facilities to ensure the construction of a harmonious and healthy living environment.

\section{Basic Principles of Green Transformation Planning of Industrial Parks in the Era of Low-Carbon Economy}

\subsection{Green Sustainable Development Principle}

Regarding the consideration of green transformation planning of industrial parks, the principle of green and sustainable development should be adhered to in practice. While focusing on the development of the industrial economy, ecological environmental protection should be incorporated into the long-term development strategic planning of industrial parks. In the era of a low-carbon economy, managers must establish a new management concept and be able to generate specific green transformation plans in terms of product production, equipment use, and space layout. Industrial parks should focus on continuously improving energy utilization and effectively solving the problems of environmental pollution and noise pollution caused by industrial production. Renewable energy technology and energy-saving technology will be scientifically applied to the green transformation project of the industrial park and generate a low-carbon industrial structure with realistic adaptability. Upgrade from high quality and high energy consumption production to low consumption, low emission, and intelligent production, and build an energy-saving industrial park.

\subsection{The Principle of Efficient Service to People}

In the process of green and sustainable development of the industrial park, it is necessary to manage "things" intelligently and modernly, but also to serve "people" efficiently. Adhering to this basic principle, we should carry out the green transformation of industrial parks in an orderly manner. Whether for the operators, producers, and technicians in the park or the city residents outside the park, we should strive to build a comfortable and healthy living environment. In the process of production and operation, energy-saving and emission reduction should be consciously carried out to optimize the park environment. Handling the complex relationship between people and enterprises, enterprises and enterprises, and enterprises and society, all personnel can carry out production and operation activities with the principle of serving the people, and give active support and feedback to the green transformation plan of the industrial park.

\subsection{The Principle of Green and Wisdom Development of Industrial Park}

In the era of a low-carbon economy, the development and innovation of indus- 
trial parks should actively implement and enforce the concept of sustainable development. It should adhere to the principle of green and wisdom development, upgrade the public service equipment green, and carry out the green transformation of all systems in the industrial park. In the process of making specific work plans and programs, a comprehensive understanding of noise pollution and water pollution in industrial parks is needed. In this way, we can think about all aspects of the work on the underground waterway system and the construction of roads outside the park. Through scientific green transformation planning, the service functions of industrial parks can be effectively enriched and expanded. While comprehensively enhancing the efficiency of industrial economic development, it dynamically optimizes the ecological environment and enables human beings to live in harmony with nature. At the same time, the green transformation and upgrading of industrial parks should be able to construct and improve the industrial chain in a targeted manner according to the effect of its own industrial transformation and upgrading, as well as the goal of green development. We should make a deep connection between economic development and ecological environmental protection, and promote the green transformation project of industrial parks in a sustainable and scientific way.

\section{The Logical Framework of Green Transformation of Industrial Park in the Era of Low-Carbon Economy}

\subsection{Improve the Green Industrial Chain of Industrial Park}

In the era of a low-carbon economy, industrial parks should persevere to the principle of sustainable development and actively carry out green transformation planning in the process of actually carrying out production and operation activities. That is, in terms of technological innovation and industrial innovation, all of them should gradually improve the green industrial chain. According to the strategic thought of China's green and sustainable economy, the work target is precisely positioned, and the production resources are integrated and allocated scientifically with the enterprises as the main objects. In the process of deeply participating in the increasingly fierce market competition, the relationship of production factors in the industrial park should be effectively handled. Taking the leading industry of the industrial park as the key, we need to build a perfect green industrial chain. In the process of optimizing the industrial structure, it is necessary to establish new thinking about the transformation of by-products in industrial parks.

The green transformation planning of industrial parks should help upgrade the whole industrial system. Both the spatial layout and infrastructure construction should adhere to the concept of green and sustainable development to deal with each production factor. Ensure the circular flow of production resources, achieve integration in raw materials and materials, product production, technology integration and innovation, marketing, logistics service, and after-sales service, etc. Based on a perfect supply system, the industrial park is prompted to 
gradually realize low consumption, high production, and efficient management.

\subsection{Enhance the Effectiveness of Green Manufacturing}

Green production and manufacturing is the key to the efficient realization of the goal of green transformation planning in industrial parks. In the process of green upgrading of the production system, the recycling planning of the park should be done. That is while emphasizing the improvement of product quality and efficiency, the treatment of pollutants should be increased and the probability of environmental moistening and water pollution should be minimized [1]. Industrial parks should continuously improve and optimize the green manufacturing system, being able to gain new inspiration and insight from the established working problems and the concept of a low carbon economy. The process of focusing on the development of pillar industries should deal with the relationship between people and nature, the contradiction between economic development and ecological environmental protection. The process of green transformation planning work in industrial zones should make every effort to enhance the effectiveness of green manufacturing to gradually achieve high utilization of operational and production resources. Managers need to develop scientific green management mechanisms and planning based on the life cycle of manufacturing, as well as the production volume and production scale of the practice. This requires that the process of manufacturing industrial equipment and production accessories should be clean, low-carbon and green, and ultimately produce goods that meet the standards.

\subsection{Modernization of Industrial Park Environmental Management}

In the era of a low-carbon economy, the green transformation planning of industrial parks is not only an important measure to achieve sustainable and healthy development, but also a necessary measure to support the establishment of a charming China and healthy industrial upgrading and transformation of the country. Relevant personnel should be able to drive the efficient promotion of green transformation planning with technological innovation and optimize the workflow and procedures by using modern information technology [2] [3]. By gradually realizing the modernization of environmental management in industrial parks, the quality and efficiency of pollution control will be continuously improved.

More importantly, the green renovation and planning of industrial parks should be somewhat contemporary and wise. That is, according to the development requirements of a low-carbon economy, green transformation strategies and sustainable development plans with realistic adaptability should be formulated. The wisdom is not only reflected in the application of the latest energy-saving technology, artificial intelligence, and other technologies, but also the change of management thinking. From the perspective of realistic thinking and a low-carbon economy, we design low-carbon planning and green transformation 
plans for the park. Efficient environmental management can promote the overall improvement of the green development level of industrial parks. Using the visualization management mode, we will deeply promote the wisdom construction and ecological construction of industrial parks.

\subsection{Green Upgrade of Hardware and Equipment in Industrial Parks}

Under the era of a low-carbon economy, the green transformation planning for industrial parks should show certain international commonalities. We need to make green renovations and upgrades in infrastructure and ensure that hardware equipment and facilities have shared functions to ensure a significant increase in resource utilization. Whether maintaining and upgrading old infrastructure or building new waste treatment facilities, ensure that they demonstrate significant green, healthy and sustainable use. For example, in the process of treating sewage in industrial parks, we should pay attention to the integrated innovation of technology and combine advanced facilities and equipment to provide the quality and efficiency of sewage treatment comprehensively [4] [5]. For the low-carbon upgrade carried out in industrial parks, a new understanding should be established for the sharing of infrastructure equipment, and it should be taken as an important means of green transformation planning to reach the management effect of twice the result with half the effort.

\section{The Main Measures of Green Transformation of Industrial Park in the Era of Low-Carbon Economy}

\subsection{Construction of Industrial Park Green Development Quality Evaluation System}

Under the low-carbon economy, the implementation of green transformation actions in industrial parks should be targeted and effective. The key influencing factors triggering environmental pollution problems are clearly identified, and a perfect and scientific evaluation system for the green development quality of industrial parks is constructed with this guidance. Whether carrying out daily management and operation work or promoting the green transformation planning project of industrial parks, dynamic evaluation and assessment should be carried out according to the work process [6]. A scientific environmental evaluation system is formulated for industrial wastewater pollution and noise pollution, etc. Industrial parks should continuously improve and optimize low-carbon planning with realistic green development and low-carbon management posture. On the basis of fully ensuring the orderly operation of the economic system and ecosystem of the industrial park, it should give positive feedback to the green and low-carbon policies and guidelines proposed by the local government. Under the guidance of correct policies, the green transformation planning of industrial parks is carried out with clear objectives. Relying on the perfect industrial park green development quality evaluation system, we can understand the prob- 
lems and shortcomings of our own low-carbon planning in time, so as to modify the planning and green transformation plan in time. For example, for the resource consumption index of the industrial park, it combines energy saving, multiple use of resources, utilization and treatment of water resources, comprehensive energy consumption of enterprises, industrial land and other indicators to make a comprehensive evaluation.

Therefore, it is necessary to continuously revise and improve the green development goals and strategic planning of industrial parks and to solve problems according to the needs, and formulate targeted green transformation plans. From the dimensions of economy, resources, and environment, the green development and green transformation of industrial parks are dynamically evaluated to ensure that they meet the requirements of production and management in the era of the low-carbon economy.

\subsection{Develop a Green Planning Mechanism in Line with the Background of Low-Carbon Economy}

Management, production, and ecological construction are the three key elements in the transformation and upgrading of the green transformation plan of the industrial park. It needs to develop a green planning mechanism that meets the requirements of a low-carbon economy, and gradually realize green operation and individual energy-saving management through institutional reform and innovation. In the process of optimizing the outdoor environment, industrial zones can make use of ecological corridors for the green transformation of spatial layout [7]. In this way, not only can the green area of the industrial park be improved, but also the ecological balance development can be promoted. Green water plants are used to solve the heat island effect of industrial parks and provide people with a comfortable and healthy working environment. For the road system, underground pipe network, power supply system, and other projects in the industrial park, scientific and strict green renovation planning system and the process should be formulated respectively. With the profound connotation of the concept of low-carbon economy as a reference, green renovation is carried out for projects with radiation and aging. When greening planning for roads, managers should conduct scientific research on geological conditions and vegetation growth habits to avoid problems of soil erosion and increased costs of green renovation planning. The low-carbon economy is carried out throughout the whole transformation project, and a perfect and scientific planning mechanism for the green transformation of industrial parks is constructed. According to the preset standards, processes, and planning, we will implement all the work in an orderly and standardized manner. In particular, in the process of green transformation of the drainage system of the industrial park, it is necessary to carry out intelligent and centralized treatment of industrial sewage to avoid the problem of secondary pollution. The drainage system should be designed and planned in a modernized way, and the excessive exploitation of groundwater or the discharge of sewage into the ground should be stopped. 
In response to these tasks, the person in charge of the industrial park must formulate a scientific management system. The overall advancement of the green transformation planning of industrial parks is driven by institutional innovation, to gradually form a low-consumption and high-efficiency development trend.

\subsection{Formulate Green Economic Cycle Development Mode}

In the era of a low-carbon economy, for the study of green transformation planning of industrial parks, managers need to carry out macroscopic regulation and global control. It should be able to strictly comply with the principle of circular economy development, and carry out green transformation and upgrading of industrial parks [8]. The integration and planning of the established resources should be done well, and there should not be the problem of wasting resources for the sake of seeking new changes, which is contradictory to the initial vision of green transformation. Managers need to conduct comprehensive research and think about the specific spatial layout, operation of facilities and equipment, and greening of the current industrial park. In the process of green transformation of existing facilities and equipment, the basic principle of low carbon and green should be insisted. We should formulate a green economic cycle development model that meets real needs and requirements, and carry out the green transformation of industrial parks with goals and strategies. Based on the principle of material regeneration, industrial manufacturing and green planning are scientifically integrated to further improve the industrial chain of low-carbon economy.

The green circular economy emphasized here places more emphasis on achieving low consumption in the operation and production process, and recycling the trimmings as much as possible. While ensuring the overall development quality of the industrial park, more funds should be invested in ecological and environmental protection. In terms of pollution control and energy conservation and emission reduction, industrial parks should do a good job in transforming the market of energy-saving technology. In terms of pollution control and energy conservation and emission reduction, industrial parks should do a good job in the market transformation of energy-saving technologies. Ensure that while using high technology to upgrade and plan green industrial parks, greater economic benefits can also be obtained from it.

Energy-saving technology is not only a favorable tool for green transformation planning of industrial parks but also a core item for creating economic value. Through the formulation and orderly implementation of the green economy development model, we can empower the green transformation planning of industrial parks. The development of the circular economy should be run throughout the whole process of green upgrading of industrial parks, and gradually create energy-saving and high-yield industrial parks. At the same time, science and technology-based enterprises and manufacturing enterprises should carry out in-depth cooperation to develop and produce high-volume energysaving products for daily management and operation. 


\section{Conclusion}

In conclusion, the green transformation planning of industrial parks in the context of a low-carbon economy should focus on reflecting people-oriented and ecological balance protection. Managers should innovatively plan green transformation projects according to the operating characteristics and leading industries of industrial parks. At the same time, the concept of green and sustainable development is integrated into the construction of infrastructure and upgrading of system engineering. The development of green transformation of industrial parks should focus on generating sound mechanisms and innovative models to ensure the efficient use of all production resources. Comprehensive thinking from technological innovation, industrial upgrading, and system reform should be carried out to ensure the high-level completion of the green transformation and planning work of industrial parks and gradually realize the healthy and sustainable development of the industrial economy.

\section{Acknowledgements}

The author would like to thank all reviewers for their valuable comments on this thesis, which allowed us to find many details worthy of improvement and made our paper more clear and complete.

\section{Conflicts of Interest}

The author declares no conflicts of interest regarding the publication of this paper.

\section{References}

[1] Chi, Q.H. (2020) A Few Suggestions on the Design of Municipal Roads in Industrial Parks. China Residential Facilities, 54-55.

[2] Sun Z.H. (2020) Reflections and Suggestions for Energy Planning in Industrial Parks. Power Equipment Management, 22+139.

[3] Islam Sarker, M., Hossin, M., Anusara, J., Chanthamith, B. and Kumar, N. (2018) Practices of Low Carbon Economy in China: Challenges and Opportunities for Economic Development. Low Carbon Economy, 9, 18-32. https://doi.org/10.4236/lce.2018.91002

[4] Jia, B. and Jie, X.T. (2020) Exploring the Path of Building Eco-Industrial Parks in Highly Urbanized Regional Development Zones. Science and Technology Economic Journal, 128-129.

[5] Simarmata, H., Dimastanto, A., Santoso, S. and Kalsuma, D. (2014) Institutional Barriers of Low Carbon Development Planning in Indonesian Small Cities. Low Carbon Economy, 5, 105-116. https://doi.org/10.4236/lce.2014.53011

[6] Song, S.M. (2020) Rumination on the Idea of Planning Environmental Assessment of Ecological Industrial Park. China Equipment Engineering, 243-244.

[7] Lai, L. and Tu Y.D. (2020) Building a Green Economic System to Enhance the Competitiveness of Green Industries. Mass, 46-47.

[8] (2020) Building an Assembly Building Demonstration Base in Industrial Parks (Hunan Ningyuan County Housing and Urban-Rural Development Bureau). Construction, 42-43. http://www.jzzzs.com/ 